\title{
Advances in Unsteady Boundary Layer Transition Research, Part I: Theory and Modeling
}

\author{
M. T. Schobeiri and L. Wright \\ Turbomachinery Performance and Flow Research Laboratory, Department of Mechanical Engineering, \\ Texas A\&M University, College Station, Texas, USA
}

This two-part article presents recent advances in boundary layer research that deal with the unsteady boundary layer transition modeling and its validation. A new unsteady boundary layer transition model was developed based on a universal unsteady intermittency function. It accounts for the effects of periodic unsteady wake flow on the boundary layer transition. To establish the transition model, an inductive approach was implemented; the approach was based on the results of comprehensive experimental and theoretical studies of unsteady wake flow and unsteady boundary layer flow. The experiments were performed on a curved plate at a zero streamwise pressure gradient under a periodic unsteady wake flow, where the frequency of the periodic unsteady flow was varied. To validate the model, systematic experimental investigations were performed on the suction and pressure surfaces of turbine blades integrated into a high-subsonic cascade test facility, which was designed for unsteady boundary layer investigations. The analysis of the experiment's results and comparison with the model's prediction confirm the validity of the model and its ability to predict accurately the unsteady boundary layer transition.

Keywords boundary, layer, transition, unsteady

The flow in a turbomachine stage is highly turbulent and unsteady due to the interactions between the stator and the rotor. The trailing edge thickness together with the boundary layer thickness, in association with the rotational motion of the rotor, generate unsteady wakes. The unsteady wake exhibits the mean velocity defects with a high level of turbulence intensity

Received 28 March 2001; accepted 12 April 2001.

Address correspondence to M. T. Schobeiri, Turbomachinery Performance and Flow Research Laboratory, Department of Mechanical Engineering, Texas A\&M University, College Station, TX 77843-3123, USA. E-mail: tschobeiri@mengr.tamu.edu that pases through the blade rows, affecting the natural boundary layer transition. An accurate prediction of the unsteady boundary layer transition behavior is a prerequisite for a reliable calculation of the blade profile losses, heat transfer characteristics and, thus, the efficiency of the turbine or compressor stages. However, the transition process under the influence of periodic unsteady wakes is not predicted reliably by the existing steady transition models. For this reason, the current investigation focused on the transition process and its effect on the boundary layer velocity profiles and heat transfer coefficients under unsteady wake flow condition.

Studies by Abu-Ghannam and Shaw (1980), Dullenkopf and Mayle (1994), and Gostelow and Blunden (1989) were conducted to determine the effect of free-stream turbulence and pressure gradient on the spot production rate and the intermittency factor.

Significant contributions to steady and unsteady boundary layer research were made by Pfeil and his coresearchers (Eifler, 1975; Herbst, 1980; Orth, 1992; Pache, 1976; Schobeiri, 1979; Schröder, 1985). Pfeil and Herbst (1979), utilizing the squirrel cage type of wake generator and a flat plate, developed a wakeinduced transition model that is now generally accepted as being correct. They also showed that the boundary layer grew naturally in between the induced transition regions by wakes. Comprehensive investigations on the effect of periodic unsteady flow on a curved plate were performed by Schobeiri and Radke (1994) and Schobeiri et al. (1995). They showed that an increase in wake passing frequency as a result of reducing the wake spacing results in a change in the wake turbulence structure and also a shift of transition region toward the leading edge. Experiments to study the effect of unsteady wake flow on the boundary layer transition were also conducted by Hodson (1990), Orth (1992), Paxson and Mayle (1991), and Walker (1989). Paxson and Mayle investigated the effect of unsteady passing wakes on the laminar boundary layer near the stagnation region. Dullenkopf and Mayle (1991) proposed a time-averaged transition model. Few of these researchers have addressed the effect of wake frequency and structure on the boundary layer transition. 
The transition process was investigated by Emmons (1951) on the basis of the turbulent-spot production theory. This theory was later promoted by Dhawan and Narasimha (1958), who found the intermittency factor for natural transition. Unlike the case of steady boundary layer transition, the calculation of intermittency function in unsteady flow situations is a difficult task because of the distribution of the freestream turbulence, which is periodically changing from almost zero to high intensity. The process of turbulent/nonturbulent decisions based on the instantaneous signals measured under these unsteady conditions was reviewed by Hedley and Keffer (1974). They proposed derivatives of velocity signals as the detector function to identify the turbulent and nonturbulent parts in the signals. This method was also used by Antonia and Bradshaw (1971), Kovasznay (1970), and Bradshaw and Murlis (1973). Paxson and Mayle (1991) and Mayle (1991) used a similar method for unsteady flows.

Developing an unsteady-transition model is essential to accurately predicting the unsteady boundary layer characteristics, such as skin friction and heat transfer coefficients. With an appropriate transition model, it is possible to solve the boundary layer equations numerically, using various methods, such as those proposed by Launder and Spalding (1972), Crawford and Kays (1976), and Schmidt and Patankar (1991). Implementing such a model in an unsteady Navier-Stokes code enables reliable prediction of the turbomachinery profile loss coefficients and, thus, of the efficiency. Based on the fundamental investigations of steady and unsteady wake flows by Schobeiri and his coworkers (1994, 1995, 1996), Chakka and Schobeiri (1999) established the first unsteady boundary transition model to account for the effect of periodic unsteady wakes on the boundary transition. This article briefly describes the experimental investigations that provided the basis for the inductive approach previously mentioned. To validate the transition model, it was applied to an unsteady turbine cascade flow with distinctively different pressure distributions on the suction and pressure surfaces.

\section{EXPERIMENTAL INVESTIGATIONS}

For developing and validating the transition model presented in this paper, two experimental research facilities were developed and designed. The first facility provided the systematic data for understanding the fundamental physical aspects of the unsteady wake flow and its interaction with the boundary layer. The data were essential in establishing an inductive theory, which is the basis of the unsteady boundary layer transition model. The second facility was designed to validate the transition model.

\section{Experimental Facility for Fundamental Unsteady Boundary Layer Research}

Systematic experimental data were obtained using a subsonic wind tunnel test facility. This facility has been described in several publications (Chakka and Schobeiri, 1999; Schobeiri and Radke, 1994; and Schobeiri et al., 1995), so only a brief description will be given here. The facility consists of a large centrifugal fan, a settling chamber, a nozzle, a wake generator, and a curved test section. The relevant flow parameters are listed in Table 1. The squirrel cage type of wake generator shown in Figure 1 generates the unsteady flow condition present at the inlet of the test section. The wake generator consists of two parallel, rotating circular disks in which rods can be circumferentially arranged. To determine the effects of wake passing frequency and structure on boundary layer transition, five different rod spacings are used (see Table 1). The unsteady flow produced by the wake generator is characterized by an unsteady parameter $\Omega$. This parameter is similar to the Strouhal number and is defined as $\Omega=\sigma / \phi$, where $\sigma$ is the ratio between the arc length of the plate, $s_{0}$, and the spacing between the rods, $s_{R}$; and $\phi$ is the ratio of the inlet velocity, $U_{i n}$, and the circumferential velocity of the wake generator, $U_{w}$. The values of $\Omega$ cover a broad range that are typical of a turbomachine; they are specified in Table 1. Two distinct curved plates, which simulate the pressure surface of a turbine blade, were utilized in this investigation. The first was a curved plate for aerodynamic measurements and the second a heat-transfer curved plate with the same concave dimensions as the aerodynamic plate. The test section with the wake generator, curved plate, and instrumentation is shown in Figure 1.

Boundary layer measurements were taken on the concave surface of the aerodynamic plate for $\Omega=0,1.033,1.725,3.443$, and

TABLE 1

Specifications of the Inlet Flow and the Wake Generator

\begin{tabular}{llll}
\hline \multicolumn{1}{c}{ Parameters } & \multicolumn{1}{c}{ Values } & \multicolumn{1}{c}{ Parameters } & \multicolumn{1}{c}{ Values } \\
\hline Nozzle exit Reynolds number & Re $h=0.43 \times 10^{6}$ & Nozzle exit turbulence intensity & $\mathrm{Tu}=1.20 \%$ \\
Nozzle exit height & $h=420.00 \mathrm{~mm}$ & Nozzle exit width & $w=593.00 \mathrm{~mm}$ \\
Steady reference (0 rods) & $s_{R}=\infty \mathrm{mm}$ & $\Omega$ parameter steady case & $\Omega=0.0$ \\
Set 1 rod spacing & $s_{R}=314.0 \mathrm{~mm}$ & $\Omega$ parameter for set 1 & $\Omega=1.033$ \\
Set 2 rod spacing & $s_{R}=188.4 \mathrm{~mm}$ & $\Omega$ parameter for set 2 & $\Omega=1.725$ \\
Set 3 rod spacing & $s_{R}=94.2 \mathrm{~mm}$ & $\Omega$ parameter for set 3 & $\Omega=3.443$ \\
Set 4 rod spacing & $s_{R}=62.8 \mathrm{~mm}$ & $\Omega$ parameter for set 4 & $\Omega=5.166$ \\
Number of rods in set 1 & $n_{R}=3$ & Number of rods in set 2 & $n_{R}=5$ \\
Number of rods in set 3 & $n_{R}=15$ & Number of rods in set 4 & $n_{R}=10$ \\
\hline
\end{tabular}




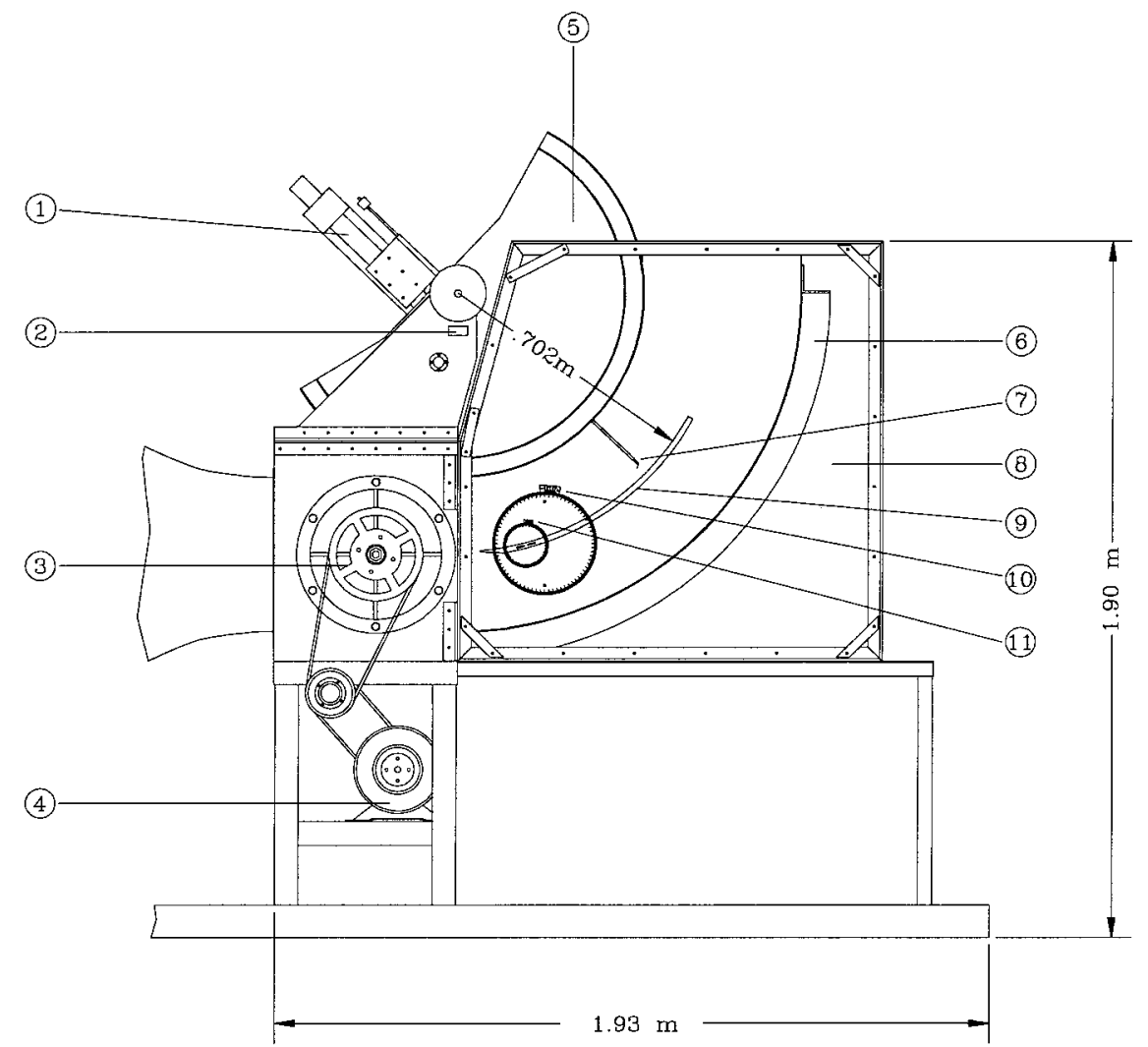

FIGURE 1

Test section. 1, traversing system; 2, nozzle; 3, wake generator; 4, electric motor; 5, convex wall; 6, concave wall; 7, hot-wire probe; 8 , plexiglass wall; 9 , curved plate; 10, small vernier; 11, large vernier.

5.116, utilizing a single-wire, hot-wire probe with a 4- $\mu \mathrm{m}$ tungsten filament. The probe was mounted on a computer-controlled linear traversing system. This system is capable of traversing in increments of $2.5 \mu \mathrm{m}$, which is essential in measuring the laminar sublayer. To capture the major portion of the transition onset, the plate was traversed in the longitudinal direction in steps of 2 degrees until $50 \%$ of the plate was reached. The next $25 \%$ of the plate was traversed in increments of 3 degrees, and the last quarter was traversed in increments of 5 degrees. For each streamwise position, the boundary layer measurements were started $0.1 \mathrm{~mm}$ above the surface of the plate and extended $10.0 \mathrm{~mm}$ above the curved plate. Starting with a high sampling frequency of $10,240 \mathrm{~Hz}$, the preliminary frequency variations showed that the same velocity, turbulence intensity, and intermittency can be reproduced with reduced sampling frequencies. Spectral analysis revealed that the sampling frequency of $2560 \mathrm{~Hz}$ is sufficient for boundary layer investigations. Thus, this frequency was chosen for all $\Omega$ values. Aerodynamic measurements were taken on the heat-transfer plate to ensure that the new plate provided similar boundary layer results so that a comparison could be made between the boundary layer and heat-transfer measurements.

\section{Unsteady Flow Turbine Cascade Experimental Facility for Model Validation}

To validate the transition model under turbomachinery flow conditions, detailed aerodynamic and heat-transfer experiments were performed on the suction and pressure surfaces of an instrumented turbine blade, which was integrated into a highsubsonic, unsteady flow turbine cascade research facility, shown in Figure 2. This facility has already been described by Schobeiri et al. (1995a) and Schobeiri and Pappu (1999), so only a brief description will be given here.

The facility consists of a large centrifugal fan, a settling chamber, a nozzle, a wake generator, and a cascade test section. The relevant geometric and flow parameters are listed in Table 2. The free-stream turbulence intensity of steady flow into the test section is $1.0 \%$. However, for unsteady flow cases, higher freestream turbulence intensities are established by wakes.

Two-dimensional periodic unsteady flow is simulated by the translational motion of a wake generator (see Figure 2), with a series of cylindrical rods attached to two parallel-operating timing belts driven by an electric motor. The special design of the facility and the length of the belts enable a considerable reduction in the measurement time when performing the boundary 

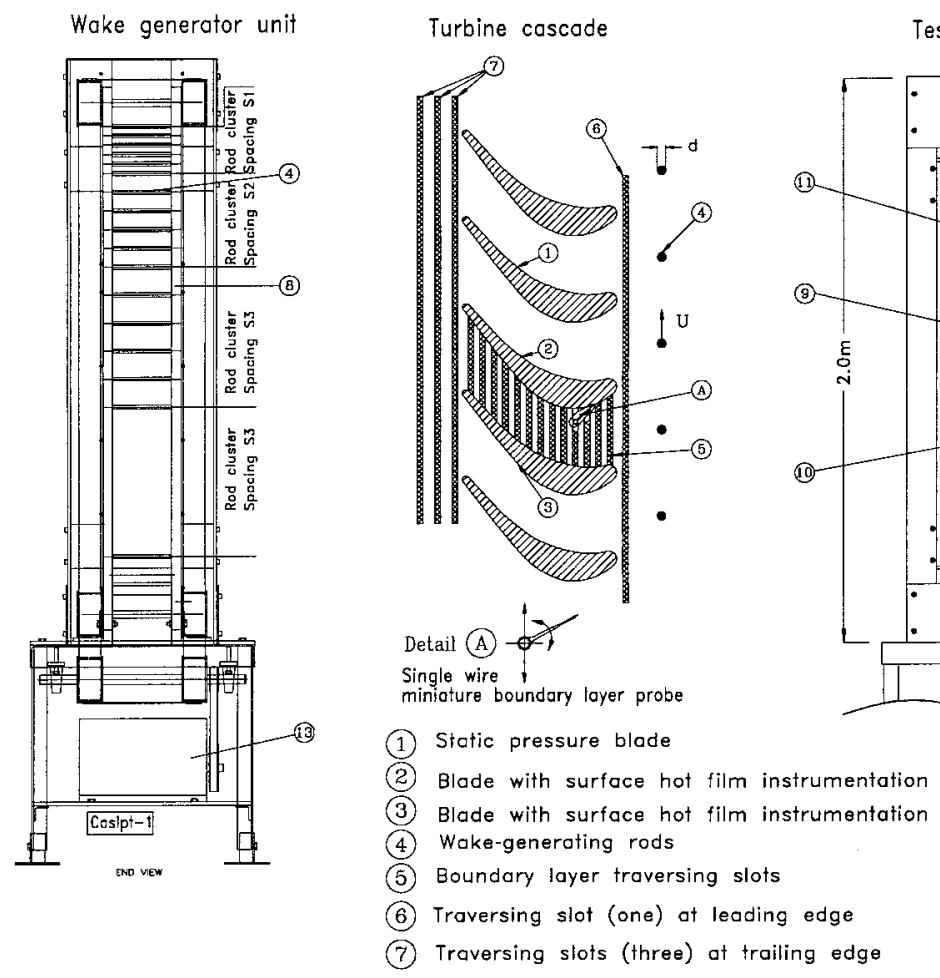

Test section

FIGURE 2

Unsteady turbine cascade research facility: test section, boundary layer traversing system, various rod clusters.

layer experiments. The research facility allows measurements of as many as four frequency ranges in one revolution. This is done by attaching up to four clusters of rods with different spacings to the two parallel timing belts moving with translational motion (see Figure 2). One of the four clusters has no rods, thus simulating the steady case. The data acquisition and analysis system separates and regroups the data before applying the unsteady ensemble average technique.

The distance between the wake generator rods and the leading edge of the turbine blade is $108 \mathrm{~mm}$. The cascade test section, shown in Figure 2, is located downstream of the wake genera- tor. Using an existing nozzle with a height of $1000.0 \mathrm{~mm}$ and a width of $200.0 \mathrm{~mm}$, the test section can include up to seven blades with a height of $200.00 \mathrm{~mm}$ and a chord up to $250.00 \mathrm{~mm}$ (Table 3). The blades are inserted between two vertical plexiglass side walls. One side wall integrates the boundary layer, the inlet, and the exit traversing slots. The turbine blades are specially manufactured to specific measurements. Boundary layer measurements are implemented using five NASA turbine blades whose geometry was described in the NASA report by Schobeiri and colleages (1991). One of these aerodynamic blades is specially manufactured to allow for static pressure measurements

TABLE 2

Specifications of Unsteady Turbine Cascade Research Facility

\begin{tabular}{llll}
\hline \multicolumn{1}{c}{ Parameters } & \multicolumn{1}{c}{ Values } & \multicolumn{1}{c}{ Parameters } & \multicolumn{1}{c}{ Values } \\
\hline Inlet velocity & $U_{\text {in }}=15 \mathrm{~m} / \mathrm{sec}$ & Blade exit metal angle & $\alpha_{1}=61.8^{\circ}$ \\
Nozzle exit height & $H_{N}=1000 \mathrm{~mm}$ & Nozzle exit width & $W_{N}=200.0 \mathrm{~mm}$ \\
Blade inlet flow angle & $\alpha_{1}=0^{\circ}$ & Blade spacing & $S_{B}=159.31 \mathrm{~mm}$ \\
Blade height & $L=200.0 \mathrm{~mm}$ & Blade Re number & $\operatorname{Re}_{c}=264,187$ \\
Blade chord & $c=281.8 \mathrm{~mm}$ & Cascade flow coefficient & $\phi=2.14$ \\
Cascade solidity & $\sigma=1.76$ & Rod diameter & $D_{R}=5.0 \mathrm{~mm}$ \\
Steady reference point & $s_{R}=\infty \mathrm{mm}$ & $\Omega$ parameter steady case & $\Omega .0$ \\
Cluster 1 rod spacing & $s_{R}=160.0 \mathrm{~mm}$ & $\Omega$ parameter for cluster 1 & $\Omega=0.755$ \\
Cluster 2 rod spacing & $s_{R}=80.0 \mathrm{~mm}$ & $\Omega$ parameter for cluster 2 & $\Omega=1.51$ \\
Number of rods in cluster 1 & $n_{R}=14$ & Number of rods in cluster 2 & $n_{R}=21$ \\
\hline
\end{tabular}


TABLE 3

Constants in the Intermittency Correlation

\begin{tabular}{lllll}
\hline & \multicolumn{4}{c}{ Reduced Frequency, $\Omega$} \\
\cline { 2 - 5 } Constants & 1.033 & 1.725 & 3.443 & 5.166 \\
\hline$c_{1}$ & 0.57 & 0.22 & 0.50 & 0.35 \\
$c_{2}$ & 0.80 & 0.85 & 0.86 & 0.88 \\
$c_{3}$ & 1.00 & 0.82 & 0.80 & 0.80 \\
$c_{4}$ & 0.85 & 0.92 & 0.92 & 0.94 \\
\hline
\end{tabular}

over the blade surface. A separate blade is manufactured with a copper internal core to allow for heat-transfer measurements. A sheet of liquid crystal is glued onto the surface of the heattransfer blade to allow for temperature measurements. The unsteady flow produced by the wake generator is characterized by an unsteady parameter $\Omega$. This parameter is similar to the Strouhal number and is defined as

$$
\Omega=\frac{\sigma S_{B}}{\phi s_{R}}
$$

where $\sigma$ is the cascade solidity and $\phi$ is the flow coefficient. The values of $\Omega$ cover a broad range that are typical of turbomachines and are specified in Table 3.

\section{INTERMITTENCY ANALYSIS}

The intermittency distribution that identifies the flow as being laminar or turbulent inside the boundary layer was calculated following the method of Hedley and Keffer (1974). Instantaneous velocities were used to identify this intermittency distribution. Representative plots of ensemble-averaged velocity signals inside the boundary layer are given in Figure 3. The instantaneous

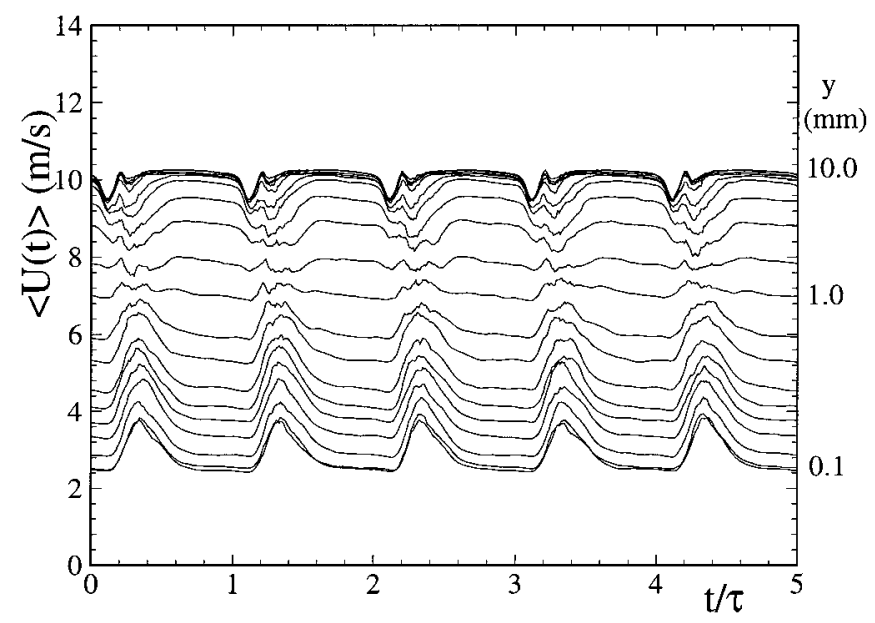

FIGURE 3

Ensemble-averaged velocity distribution as a function of nondimensional time at different $y$ locations at an $s / s_{0}$ of 0.25 for five rods. velocity was sensitized to increase its discriminatory capabilities between turbulent and nonturbulent parts of the signal. For this purpose, the second derivative of the velocity signal was used and squared for further analysis and was called the detector function. The detector function, a derivative of the velocity signals, has zeros within the fully turbulent flow. To avoid the influence of such legitimate zeros, the signal was integrated over a short time interval, resulting in criterion function, $S(t)$. Then a threshold level, $C$, was applied to this criterion function so as to distinguish between the true turbulence and the signal noise that inevitably exists, regardless of the choice of detector function.

$$
I(t)=\left\{\begin{array}{lll}
1 & \text { when } & S(t) \geq C \\
0 & \text { when } & S(t)<C
\end{array}\right.
$$

After applying the threshold level to the criterion function, $S(t)$, the result was a random square wave, with 0 s representing the laminar case and $1 \mathrm{~s}$ representing the turbulent behavior of the boundary layer. This square wave was ensemble-averaged to get the ensemble-averaged intermittency, as follows:

$$
\left\langle\gamma_{i}\left(t_{i}\right)\right\rangle=\frac{1}{n} \sum_{j=1}^{n} I_{i j}\left(t_{i}\right)
$$

where $n$ is the number of revolutions of the wake generator for which the data is collected. For a time-averaged intermittency, $\left\langle\gamma_{i}\left(t_{i}\right)\right\rangle$ was integrated with respect to time to give

$$
\bar{\gamma}=\frac{1}{T} \int_{t=0}^{T}\left\langle\gamma_{i}\left(t_{i}\right)\right\rangle d t
$$

The intermittency distribution as a function of nondimensional time is shown in Figures $4 \mathrm{a}$ and $4 \mathrm{~b}$ for the 3-rod and 10-rod cases. Similar plots are seen for other rod cases. Only the first two wakes are plotted, for better comparison of the effects of impinging wake frequency on the transition process. Intermittency is approximately equal to zero outside the wake region, near the leading edge showing the nonturbulent behavior of the flow. Wake is represented by a thin strip with intermittency values close to one, typical of a turbulent flow. As these wakes pass through the channel, the boundary layer periodically switches from laminar to turbulent, depending on their presence. The natural transition of the boundary layer is affected by periodic passing of wakes, resulting in wake-induced transition. The intermittency distributions in Figures $4 \mathrm{a}$ and $4 \mathrm{~b}$ clearly show the unsteady nature of the boundary layer transition. In this form, however, they cannot be used to quantitatively describe the complex unsteady transition process. To establish the basic relations essential for a quantitative description of the unsteady boundary layer transition, we resorted to the fundamental studies by Schobeiri and his coworkers (1996) that deal with the physics of steady and unsteady wake development in a curved environment. These studies show clearly that the turbulence structure of the steady and unsteady wake flow is determined by the wake defect, 

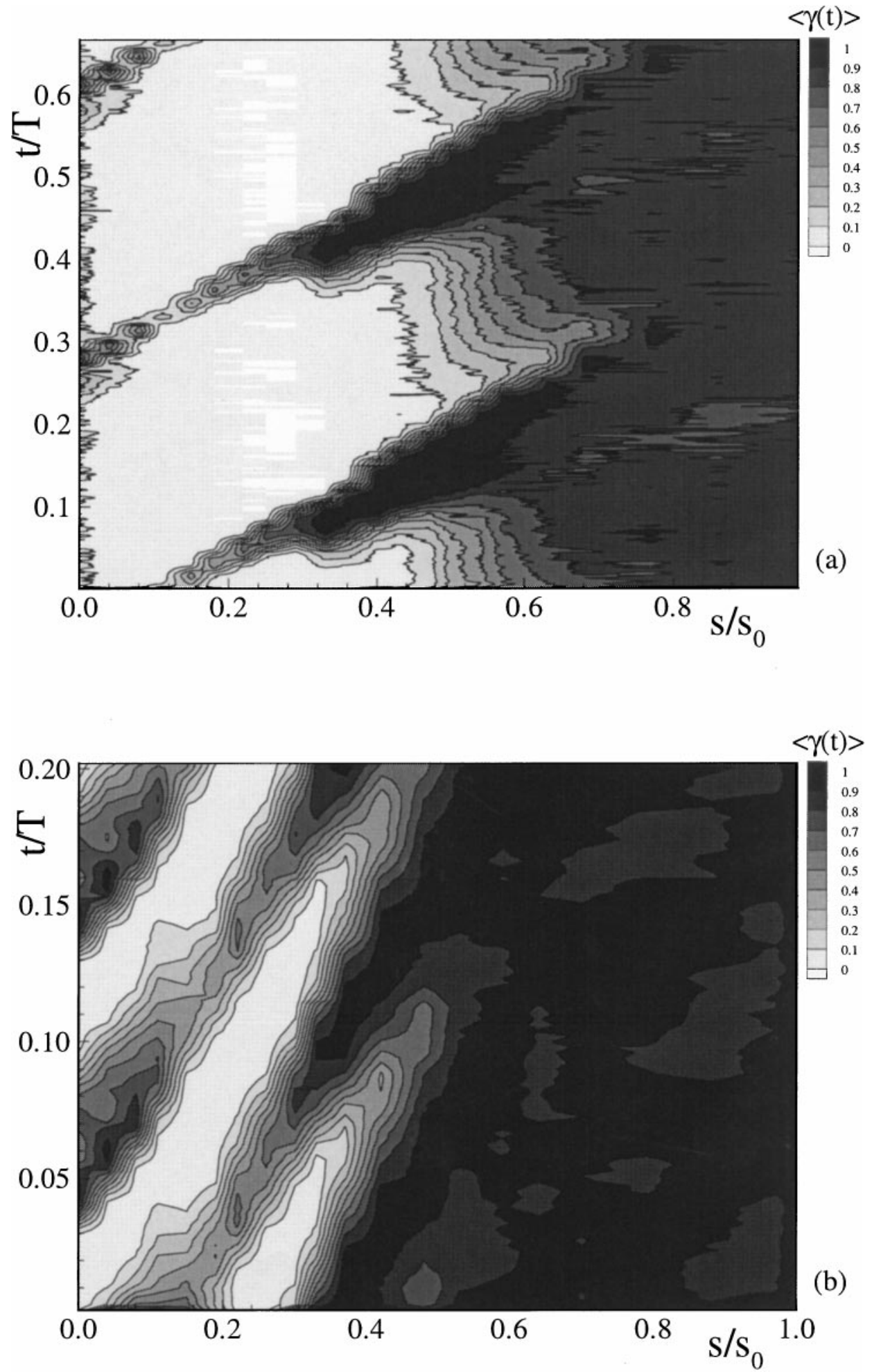

FIGURE 4

Contour plots of the intermittency factor as a function of normalized axial distance $s / s_{0}$. (a) $\Omega=1.033$ (three rods); (b) $\Omega=3.443$ (ten rods). 
which is a Gaussian function. Following the above studies, we define a dimensionless parameter,

$$
\zeta=\frac{U_{w} t}{b}=\frac{y}{b} \quad \text { with } \quad b=\frac{1}{\sqrt{\pi}} \int_{-\infty}^{+\infty} \Gamma d \xi_{2}
$$

that relates the passing time, $t$, of a wake impinging on the plate surface with the wake-passing velocity in lateral direction, $U_{w}$, and the intermittency width, $b$. The latter is directly related to the wake width introduced by Schobeiri and his coworkers (1996). In a way analogous to finding the defect function, we defined the relative intermittency function $\Gamma$ as

$$
\Gamma=\frac{\left\langle\gamma_{i}\left(t_{i}\right)\right\rangle-\left\langle\gamma_{i}\left(t_{i}\right)\right\rangle_{\min }}{\left\langle\gamma_{i}\left(t_{i}\right)\right\rangle_{\max }-\left\langle\gamma_{i}\left(t_{i}\right)\right\rangle_{\min }}
$$

In the above equation, $\left\langle\gamma_{i}\left(t_{i}\right)\right\rangle$ is the time-dependent, ensemble-averaged intermittency function, which determines the transitional nature of an unsteady boundary layer. The maximum intermittency $\left\langle\gamma_{i}\left(t_{i}\right)\right\rangle_{\max }$ exhibits the time-dependent ensemble-averaged intermittency value inside the wake vortical core. Finally, the minimum intermittency $\left\langle\gamma_{i}\left(t_{i}\right)\right\rangle_{\min }$ represents the ensemble-averaged intermittency values outside the wake vortical core. The experimental results presented in Part II of this paper show that the relative intermittency function $\Gamma$ closely follows a Gaussian distribution, which is given by

$$
\Gamma=e^{-\zeta^{2}}
$$

Here, $\zeta$ is the nondimensionalized lateral-length scale. Using this function as a generally valid intermittency relationship for zero-pressure gradient cases, the intermittency function $\left\langle\gamma_{i}\left(t_{i}\right)\right\rangle$ is completely determined if additional information about the minimum and maximum intermittency functions $\left\langle\gamma_{i}\left(t_{i}\right)\right\rangle_{\min }$ and $\left\langle\gamma_{i}\left(t_{i}\right)\right\rangle_{\max }$ are available. The experimental results in Part II of this paper show that the maximum intermittency can be described by

$$
\langle\gamma(t)\rangle_{\max }=\left(1.0-c_{1} e^{-\left(\frac{\mathrm{Re}_{x}-\mathrm{Re}_{x, s}}{\mathrm{Re}_{x, s}-\mathrm{R}_{x}, e}\right)^{2}}\right)
$$

where the constant $c_{1}$ dependents on $\Omega$. Likewise, the minimum intermittency is described by

$$
\langle\gamma(t)\rangle_{\min }=c_{2}\left(1.0-e^{-\left(\frac{\operatorname{Rex}_{x}-\operatorname{Re}_{x, s}}{\operatorname{Re}_{x, s}-\mathrm{Re}_{x, e}}\right)^{2}}\right)
$$

where the constants $c_{2}$ are again dependent on $\Omega$. The timeaveraged intermittency is described by

$$
\bar{\gamma}=c_{4}\left(1.0-c_{3} e^{-\left(\frac{\mathrm{Re}-\mathrm{Re}_{x, s}}{\operatorname{Re}_{x, t}-\mathrm{Re}_{x, e}}\right)^{2}}\right)
$$

The combined effect of $\left\langle\gamma_{i}\left(t_{i}\right)\right\rangle_{\max }$ and $\left\langle\gamma_{i}\left(t_{i}\right)\right\rangle_{\min }$ can be seen in the expression for $\bar{\gamma}$ through the constants $c_{3}$ and $c_{4}$. The four constants for the frequencies under investigation are given in Table 2. For natural transition, the above constants approach unity.

\section{Freestream Turbulence Intensity}

One of the major parameters affecting the boundary layer transition onset is the free-stream turbulence intensity. The presence of wakes, particularly their spacing and interaction, contributes significantly to an increase in the freestream turbulence. It is shown in Part II of this paper that there is a unique functional relationship between the turbulence intensity and the unsteady parameter $\Omega$.

\section{IMPLEMENTATION OF THE TRANSITION MODEL INTO CALCULATION PROCEDURES}

The developed transition model can be implemented into any Navier-Stokes or differential boundary layer code. We chose TEXSTAN, developed by Crawford and Kays (1976), which simultaneously solves differential equations of continuity, momentum, and energy. All of these equations are time-averaged and are written to describe the flow over an axisymmetrical body. The time-averaged continuity equation is given by

$$
\frac{\partial}{\partial x}(r \rho U)+\frac{\partial}{\partial y}(r \rho V)=0
$$

The time-averaged momentum equation in the $x$-direction is

$$
\rho U \frac{\partial U}{\partial x}+\rho V \frac{\partial U}{\partial y}=-\frac{d p}{d x}+\frac{1}{r} \frac{\partial}{\partial y}\left[r\left(\mu \frac{\partial U}{\partial y}-\rho \overline{u^{\prime} v^{\prime}}\right)\right]
$$

In this momentum equation, the turbulent shear stress is modeled by the eddy diffusivity for momentum and is defined as

$$
-\overline{u^{\prime} v^{\prime}}=\epsilon_{M} \frac{\partial U}{\partial y}=\frac{\mu_{t}}{\rho} \frac{\partial U}{\partial y}
$$

where $\mu_{t}$ is the turbulent viscosity, which combines with the laminar viscosity to give

$$
\mu_{\text {eff }}=\left(\mu+\mu_{t}\right)=\rho\left(\nu+\epsilon_{M}\right)
$$

Similarly, after introducing the concept of eddy diffusivity for heat, $\epsilon_{H}$, the energy equation becomes

$$
\begin{aligned}
& \rho U \frac{\partial I^{*}}{\partial x}+\rho V \frac{\partial I^{*}}{\partial y} \\
& =\frac{1}{r} \frac{\partial}{\partial y}\left\{r\left[\frac{\mu_{\text {eff }}}{\operatorname{Pr}_{\text {eff }}} \frac{\partial I^{*}}{\partial y}+\frac{\mu_{\text {eff }}}{J}\left(1-\frac{1}{\operatorname{Pr}_{\text {eff }}}\right) \frac{\partial}{\partial y}\left(\frac{U^{2}}{2}\right)\right]\right\}
\end{aligned}
$$


where $I^{*}$ is the stagnation enthalpy and $\operatorname{Pr}_{\text {eff }}$ is the effective Prandtl number, defined as

$$
\operatorname{Pr}_{e f f}=\frac{\mu_{e f f}}{(k / c)_{e f f}}=\frac{1+\frac{\epsilon_{M}}{v}}{\frac{1}{\operatorname{Pr}}+\frac{\epsilon_{M}}{v} \frac{1}{\operatorname{Pr}_{t}}}
$$

and $\operatorname{Pr}_{t}$ is the turbulent Prandtl number, given by

$$
\operatorname{Pr}_{t}=\frac{\epsilon_{M}}{\epsilon_{H}}
$$

The eddy viscosity term is modeled through the mixing length theory, and the above intermittency model is implemented by

$$
\epsilon_{M}=\gamma l^{2}\left|\frac{\partial U}{\partial y}\right|
$$

where $l$ is the mixing length and $\gamma$ is the intermittency. The solution process uses Patankar and Spalding's (1970) omega (nondimensional stream function) transformation. In streamfunction coordinates, the momentum equation without the body forces becomes

$$
U \frac{\partial U}{\partial x}+U \frac{\partial}{\partial \psi}\left[U v_{e f f} \frac{\partial U}{\partial \psi}\right]=-\frac{1}{\rho} \frac{d p}{d x}
$$

The boundary layer equations are integrated after nondimensionalizing the stream function and are solved numerically.

\section{CONCLUSIONS}

Part I of this article presents the unsteady boundary layer transition model, which is based on an intermittency distribution function. It includes the effects of periodic unsteady wakes on the boundary layer transition and heat transfer. The inductive approach used to develop the model was based on the analysis of the unsteady boundary layer measurements (presented in Part II) along a curved plate and the suction and pressure surfaces of a turbine blade. Instantaneous velocities inside the boundary layer were used to determine the intermittency distribution for various wake-passing frequencies. The method of Hedley and Keffer (1974) was used to distinguish between turbulent and laminar parts in the instantaneous velocity signals, and the result was ensemble-averaged to give ensemble-averaged intermittency. The transition model implemented into a boundary layer code resulted in an accurate prediction of the aerodynamic and heat-transfer quantities along the curved plate and the turbine blade.

\section{NOMENCLATURE}

b

C

$h$

$\mathrm{Nu}$
Intermittency wake width

Threshold level

Heat-transfer coefficient $\left(\mathrm{W} / \mathrm{m}^{2} \mathrm{~K}\right)$

Nusselt number based on concave arc length, $\mathrm{Nu}$; $h s_{0} / k$
$\operatorname{Pr}$

$\operatorname{Re}_{x}$

$\operatorname{Re}_{x, s}$

$\operatorname{Re}_{x, e}$

$s$

$S_{0}$

$s_{R}$

$S(t)$

$\mathrm{St}$

$t$

$T$

Tu

$\langle\mathrm{Tu}\rangle$

$U$

$\bar{U}$

$U_{\text {in }}$

$U_{w}$

$y$

$\alpha$

$\langle\gamma(t)\rangle_{\max }$

$\langle\gamma(t)\rangle_{\min }$

$\bar{\gamma}$

$\langle\gamma(t)\rangle$

$\Gamma$

$\zeta$

$v$

$\rho$

$\sigma$

$\tau$

$\phi$

$\Omega$
Prandtl number; $v / \alpha$

Local Reynolds number; $(\bar{U} s) / \nu$

Reynolds number at the beginning of transition

Reynolds number at the end of transition

Distance from plate leading edge ( $\mathrm{mm})$

Arc length of the concave surface; $690 \mathrm{~mm}$

Rod spacing

Stanton number; $h /\left(\rho C_{p} \bar{U}\right)$

Time (sec)

Time for one revolution of wake generator

Reference turbulence intensity

Ensemble-averaged turbulence intensity

Instantaneous velocity $(\mathrm{m} / \mathrm{sec})$

Time-averaged velocity $(\mathrm{m} / \mathrm{sec})$

Inlet velocity in streamwise direction $(\mathrm{m} / \mathrm{sec})$

Velocity of the wake generator $(\mathrm{m} / \mathrm{sec})$

Lateral distance from plate surface $(\mathrm{mm})$

Thermal diffusivity $\left(\mathrm{m}^{2} / \mathrm{sec}\right)$

Maximum ensemble-averaged intermittency

Minimum ensemble-averaged intermittency

Time-averaged intermittency

Ensemble-averaged intermittency

Relative turbulence intermittency

Nondimensional coordinate, $y / b$

Kinematic viscosity of air $\left(\mathrm{m}^{2} / \mathrm{sec}\right)$

Density of air $\left(\mathrm{kg} / \mathrm{m}^{3}\right)$

Length-spacing ratio, $s_{0} / S_{R}$

One wake-passing period

Velocity ratio, $U_{\text {in }} / U_{w}$

Nondimensionalized unsteady parameter; $\sigma / \phi$
Criterion function

\section{REFERENCES}

Abu-Ghannam, B. J., and Shaw, R. 1980. Natural transition of boundary layers: The effects of turbulence, pressure gradient and flow history. Journal of Mechanical Engineering Science 22:213228.

Antonia, R. A., and Bradshaw, P. 1971. Imp. College Aero. Rep. No. 71-04.

Bradshaw, P., and Murlis, J. 1973. Imp. College Aero. Tech. Note, No. 73-108.

Chakka, P., and Schobeiri, M. T. 1999. Modeling of unsteady boundary layer transition on a curved plate under periodic unsteady flow condition: Aerodynamic and heat transfer investigations. ASME Transactions, Journal of Turbomachinery 121:88-97.

Crawford, M. E., and Kays, W. M. 1976. STAN5 (TEXSTAN version): A Program for Numerical Computation of Two-Dimensional Internal and External Boundary Layer Flow (CR-2742). Washington, D.C.: National Aeronautics and Space Administration.

Dhawan, S., and Narasimha, R. 1958. Some properties of boundary layer flow during the transition from laminar to turbulent motion. Journal of Fluid Mechanics 3:418-436.

Dullenkopf, K., and Mayle, R. E. 1994. ASME Paper 94-GT-174. An account for free-stream turbulence length scale on laminar heat transfer. American Society of Mechanical Engineers. 
Eifler, J. 1975. Zur Frage der freien turbulenten Strömungen, insbesondere hinter ruhenden und bewegten Zylindern, Dissertation D-17. Technische Hochschule Darmstadt, Germany.

Emmons, H. W. 1951. The laminar-turbulent transition in the boundary layer. I. Journal of Aerospace Science 18:490-498.

Gostelow, J. P., and Blunden, A. R. 1989. Investigations of boundary layer transition in an adverse pressure gradient. ASME Journal of Turbomachinery 111:366-375.

Hedley, B. T., and Keffer, F. J. 1974. Turbulent/non-turbulent decisions in an intermittent flow. Journal of Fluid Mechanics 64:625644.

Herbst, R. 1980. Entwicklung von Strömungsgrenz: Schichten bei Instationärer Zuströmung in Turbomaschinen (dissertation D-17, Technische Hochschule, Darmstadt, Germany).

Hodson, H. P. 1990. Modeling unsteady transition and its effects on profile loss. Journal of Turbomachinery 112:691-701.

Kovasznay, L. S. G., Kibens, V., and Blackwelder, R. F. 1970. J. Fluid Mech. 41:283.

Launder, B. E., and Spalding, D. B. 1972. Mathematical Models of Turbulence. New York: Academic Press.

Mayle, R. E. 1991. The role of laminar-turbulent transition in gas turbine engines. ASME Journal of Turbomachinery 113:509-537.

Narasimha, R. 1957. On the distribution of intermittency in the transition region of a boundary layer. Journal of Aerospace Science 24:711-712.

Orth, U. 1992. Unsteady boundary-layer transition in flow periodically disturbed by wakes. ASME paper 92-GT-283. American Society of Mechanical Engineers.

Pache, W. 1976. Zur Frage der Entwicklung von Strömungsgrenzsschichten bei Instationärer Zuströmung in Turbomaschinen (dissertation D-17, Technische Hochschule, Darmstadt, Germany).

Patankar, S. V., and Spalding, D. B. 1970. Heat and Mass Transfer in Boundary Layers, 2nd ed. London: International Textbook.

Paxson, D. E., and Mayle, R. E. 1991. Laminar boundary layer interaction with an unsteady passing wake. Journal of Turbomachinery 113:419-427.
Pfeil, H., and Herbst, R. 1979. Transition Procedure of Instationary Boundary Layers. Paper 79-GT-128. : American Society of Mechanical Engineers.

Pfeil, H., Herbst, R., and Schröder, T. 1983. Investigation of the laminarturbulent transition of boundary layers disturbed by wakes. ASME Journal of Engineering for Power 105:130-137.

Schmidt, R. C., and Patankar, S. V. 1991. Simulating boundary layer transition with low-Reynolds-number k- $\epsilon$ turbulence models. I. An evaluation of prediction characteristics; II. An approach to improving the predictions. ASME Journal of Turbomachinery 113:10-26.

Schobeiri, M. T. 1979. Theoretische und Experimentelle Untersuchungen Laminarer und Turbulenter Strömungen in Diffsoren (dissertation D-17, Technische Hochschule, Darmstadt, Germany).

Schobeiri, M. T., and Radke, R. 1994. Effects of periodic unsteady wake flow and pressure gradient on boundary layer transition along the concave surface of a curved plate. Paper 94-GT-327. American Society of Mechanical Engineers.

Schobeiri, M. T., Read, K., and Lewalle, J. 1995. Effect of unsteady wake passing frequency on boundary layer transition: Experimental investigation and wavelet analysis. Paper 95-GT-437. American Society of Mechanical Engineers.

Schobeiri, M. T., Jose, J., and Pappu, K. 1996. Development of twodimensional wakes within curved channel: Theoretical framework and experimental investigations. ASME Journal of Turbomachinery 118:506-518

Schröeder, T. 1985. Entwicklung des instationären Nachlaufs hinter quer zur Strömungsrichtung bewegten Zylindern und dessen Einfluß auf das Umschlagverhalten von ebenen Grenzschichten stromabwärts angeordneter Versuchskörper, Dissertation D-17, Technische Hochschule Darmstadt, Germany.

Walker, G. J. 1989. Modeling of transitional flow in laminar separation bubbles. Ninth International Symposium on Air-Breathing Engines 539-548.

Wright, L., and Schobeiri, M. T. 1998. The effect of periodic unsteady flow on boundary layer and heat transfer on a curved surface. ASME Transactions, Journal of Heat Transfer 120:22-33. 

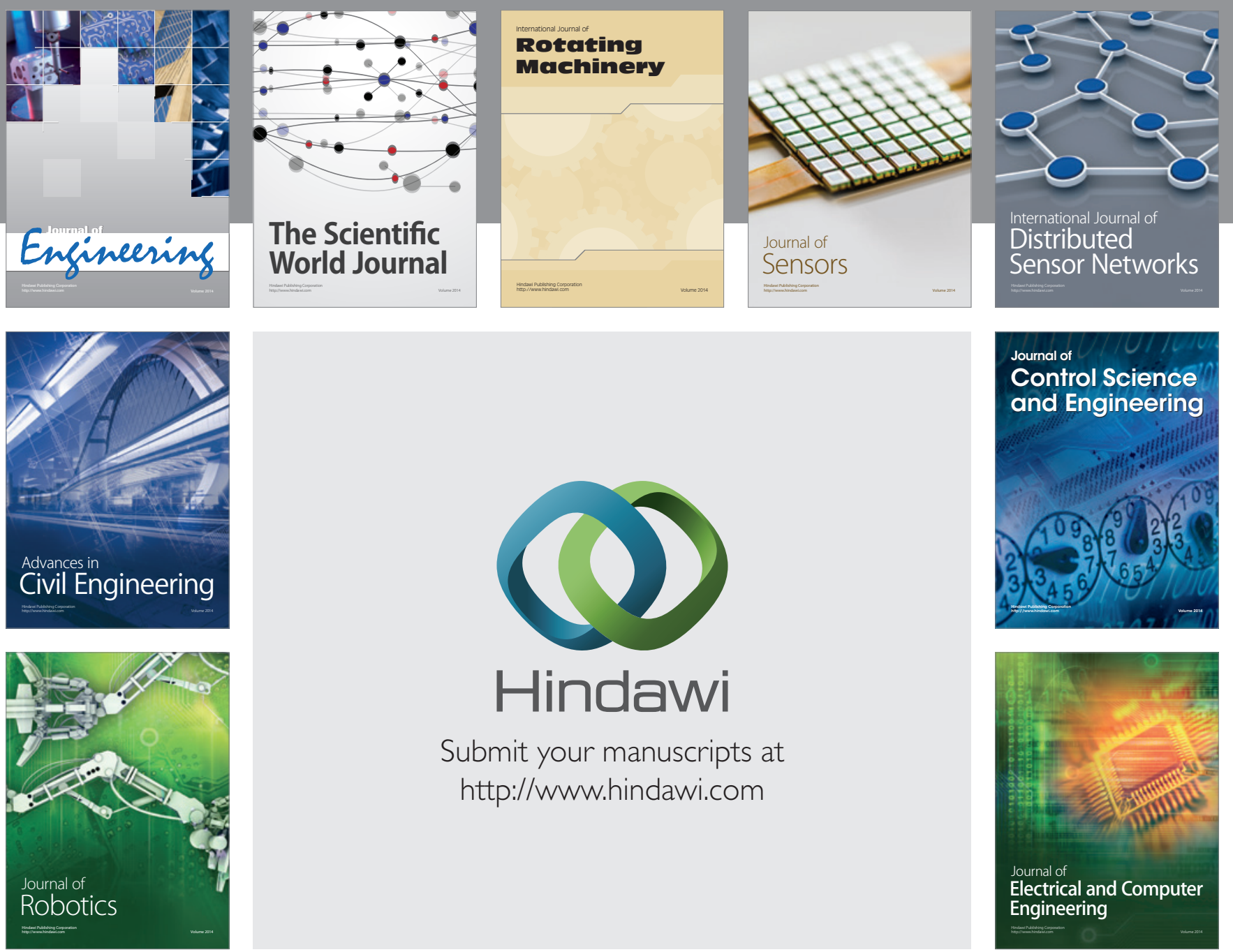

Submit your manuscripts at

http://www.hindawi.com
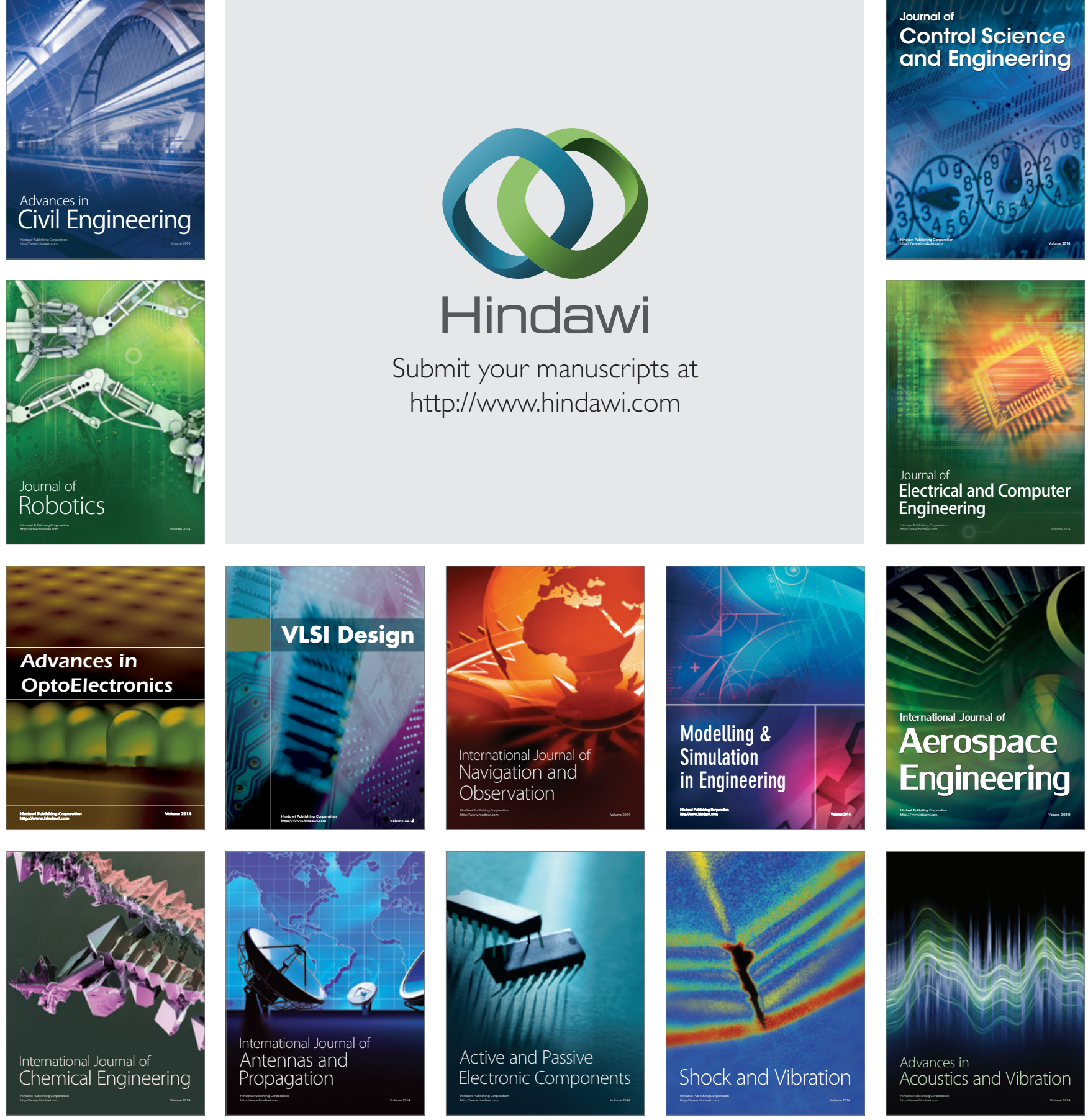